\title{
Clinical Features and Outcomes of Patients with Posterior Reversible Encephalopathy Syndrome
}

\author{
M. S. Kalaiselvan, M. K. Renuka', A. S. Arunkumar \\ Departments of Critical Care Medicine and ${ }^{1}$ Anesthesiology, Sri Ramachandra University, Chennai, Tamil Nadu, India
}

\section{Abstract}

\begin{abstract}
Aims: The aim of this study was to study the clinical features and outcomes of patients with posterior reversible encephalopathy syndrome (PRES) admitted to the Intensive Care Unit (ICU). Subjects and Methods: All adult patients admitted to our ICU with acute onset neurologic symptoms with focal vasogenic edema on magnetic resonance imaging (MRI) were included in the study. Data were collected on demography, coexisting illness, admission severity of illness, neurological symptoms, blood pressure, treatment initiated, and MRI findings. Outcome data collected included mortality, ICU average length of stay (ALOS), number of ventilator days, and neurological disability at discharge assessed by modified Rankin scale (MRS). Results: Fourteen patients were admitted with PRES. Thirteen patients were female, and their mean age was $31.5 \pm 8.3$ years. Etiology of PRES included eclampsia (64.2\%), lupus nephritis $(21.4 \%)$, CKD (7.1\%), and hypertension $(n=1[7.1 \%])$. The most common presenting symptom was seizure (92.8\%), followed by visual disturbance (42.8\%), headache (42.8\%), encephalopathy (14.2\%), and status epilepticus (14.2\%). The Glasgow coma scale on admission was $12.3 \pm 2.9$. High blood pressure was seen in 12 patients $85.7 \%$; their mean systolic and diastolic pressures were $173 \pm 10.2$ and $110 \pm 8.6 \mathrm{mmHg}$, respectively. MRI showed that parieto-occipital region was most commonly involved (92.8\%), followed by frontal lobe (42.8\%). ICU ALOS was $4.35 \pm 2.4$ days and mean ventilator days was $1.7 \pm 2.0$ days. One patient (1/14 [7.4\%]) died of multiorgan failure and 13 patients were discharged with no residual neurological deficit (MRS, 0). Conclusions: PRES is a potentially reversible disorder with prompt recognition and control of blood pressure.
\end{abstract}

Keywords: Clinical features, critically ill, eclampsia, posterior reversible encephalopathy syndrome

\section{INTRODUCTION}

Posterior reversible encephalopathy syndrome (PRES) is a clinicoradiological syndrome characterized by transient neurological symptoms such as headache, altered mental status, seizures, and visual impairment, with typical radiographic findings of vasogenic edema involving the posterior cerebral region. Although the name PRES suggests involvement of posterior circulation, the radiographic findings are rarely isolated to the posterior parieto-occipital white matter. Often, involvement of the cortex, frontal lobes, basal ganglia, and brainstem is seen. ${ }^{[1]}$ One of the characteristic features of PRES is the reversibility of the clinicoradiological abnormalities after appropriate treatment and removal of the precipitating factors..$^{[1]}$ Increased imaging of brain by magnetic resonance imaging (MRI) in the past two decades has led to increased recognition and better understanding of this syndrome. ${ }^{[2]}$ PRES is most commonly seen in patients with acute hypertension, eclampsia, autoimmune disease, cytotoxic/ immunosuppressant drugs, and renal failure. ${ }^{[3-5]}$

\begin{tabular}{|l|l|}
\hline \multicolumn{2}{|c|}{ Access this article online } \\
\hline Quick Response Code: & Website: \\
\hline & www.ijccm.org \\
\hline & \\
\hline
\end{tabular}

Our knowledge of PRES is purely based on small case series and observational studies previously described from literature. ${ }^{[3-7]}$ The majority of previous reports on PRES are from radiology and neurology specialties, and limited data are available on outcomes of patients admitted to Intensive Care Units (ICUs) with PRES. Hence, we planned to study the clinical and radiological spectrum of presentations and clinical outcomes of these patients with PRES admitted to ICU.

\section{Subjects and Methods}

This was a prospective observational study done in a tertiary care ICU. Data were collected from patients admitted to ICU

Address for correspondence: Dr. M. S. Kalaiselvan, Department of Critical Care Medicine, Sri Ramachandra University, Porur, Chennai, Tamil Nadu, India. E-mail: kalaiselvan.m.s@gmail.com

This is an open access article distributed under the terms of the Creative Commons Attribution-NonCommercial-ShareAlike 3.0 License, which allows others to remix, tweak, and build upon the work non-commercially, as long as the author is credited and the new creations are licensed under the identical terms.

For reprints contact: reprints@medknow.com

How to cite this article: Kalaiselvan MS, Renuka MK, ArunkumarAS. Clinical features and outcomes of patients with posterior reversible encephalopathy syndrome. Indian J Crit Care Med 2017;21:453-6. 
from January 2013 to December 2015. We included all adult patients admitted to our ICU with the following criteria: (1) acute onset neurologic symptoms including headache, encephalopathy, seizure, visual disturbance, or focal deficit and (2) focal vasogenic edema on brain imaging.

Data collection included demography, coexisting illness, admission severity of illness scores (APACHEII and SOFA scores), neurological symptoms, systolic and diastolic blood pressure, treatments initiated for control of blood pressure, and time taken to control blood pressure and regain consciousness. MRI features regarding location of edema and its severity and presence of hemorrhage were recorded. Primary outcomes analyzed were hospital mortality and neurological involvement as assessed by modified Rankin scale (MRS), and secondary outcomes included ICU length of stay (LOS) and number of ventilator days. Continuous variables are expressed as mean \pm standard deviation $(\mathrm{SD})$ or median with $25^{\text {th }}-75^{\text {th }}$ interquartile range (IQR), and categorical variables are expressed as numbers and percentages.

\section{RESULTS}

Fourteen patients were admitted to ICU with PRES during the study, of them 13 were female (93\%). The mean age of the patients was $31.5 \pm 10.1( \pm \mathrm{SD})$ years [Table 1$]$. The only male patient in our study presented with features of hypertensive encephalopathy. The etiology of PRES in 13 female patients included eclampsia $(n=9,64 \%)$, lupus nephritis $(n=3,21 \%)$, and end-stage renal disease (ESRD) $(n=1,7 \%)$. Of the nine patients with eclampsia, seven were postpartum eclampsia and two patients had antepartum eclampsia.

The most common presenting symptom in PRES was seizures $(93 \%)$, followed by headache $(43 \%)$, visual disturbance $(43 \%)$, and coma (14\%) [Figure 1]. Of the 13 patients with seizures, two patients had status epilepticus (14\%). The patient with ESRD had recurrent PRES presented with right-sided hemiparesis and recovered completely with hemodialysis and control of blood pressure.

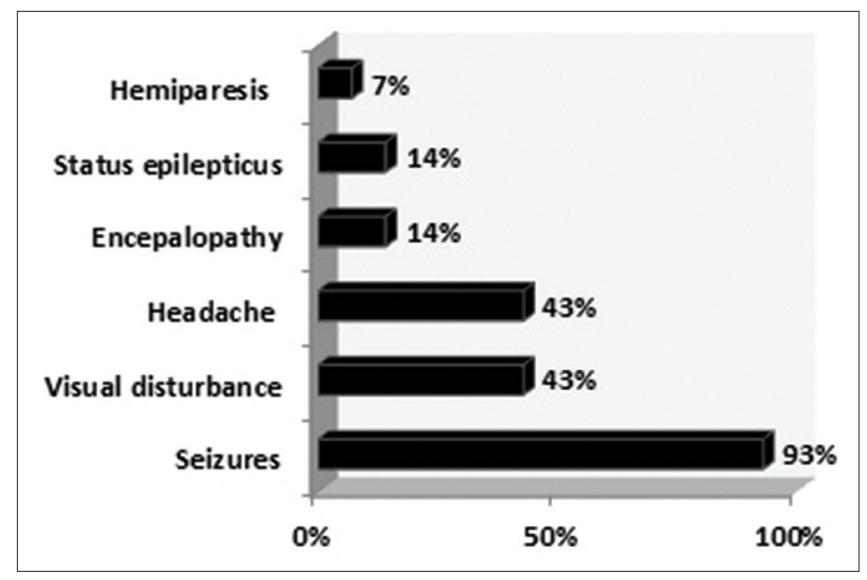

Figure 1: Clinical presentation of posterior reversible encephalopathy syndrome
Twelve patients $(86 \%)$ had high blood pressure at acute stage of presentation and their mean \pm SD systolic and diastolic blood pressures were $173 \pm 10.2$ and $110 \pm 8.6 \mathrm{mmHg}$, respectively. However, only four of these patients $(28.5 \%)$ had preexisting hypertension. Two patients (14\%) had normal blood pressure at presentation.

All patients were shifted to ICU following seizures from ward/emergency room or transferred from operating room following cesarean section. The majority of patients were admitted in postictal state to ICU, and their mean Glasgow coma scale (GCS) was $12.3 \pm 2.9( \pm \mathrm{SD})$. APACHE II and SOFA scores at admission were $8.5 \pm 6.9$ (mean $\pm \mathrm{SD}$ ) and $2 \pm 1.7$ (mean $\pm \mathrm{SD}$ ), respectively. Mean $\pm \mathrm{SD}$ serum creatinine level was $1.65 \pm 1.6 \mathrm{~g} / \mathrm{dl}$. Four patients $(28.5 \%)$ had renal failure at presentation and these patients required hemodialysis.

Parieto-occipital (92.8\%) region was most commonly involved in MRI. This was followed by frontal lobe $(42.8 \%)$, cerebellum $(21.4 \%)$, and brain stem $(21.4 \%)$ [Table 2 and Figure 2]. Two patients (14.2\%) had hemorrhage in MRI. One patient had intracerebral hemorrhage and one

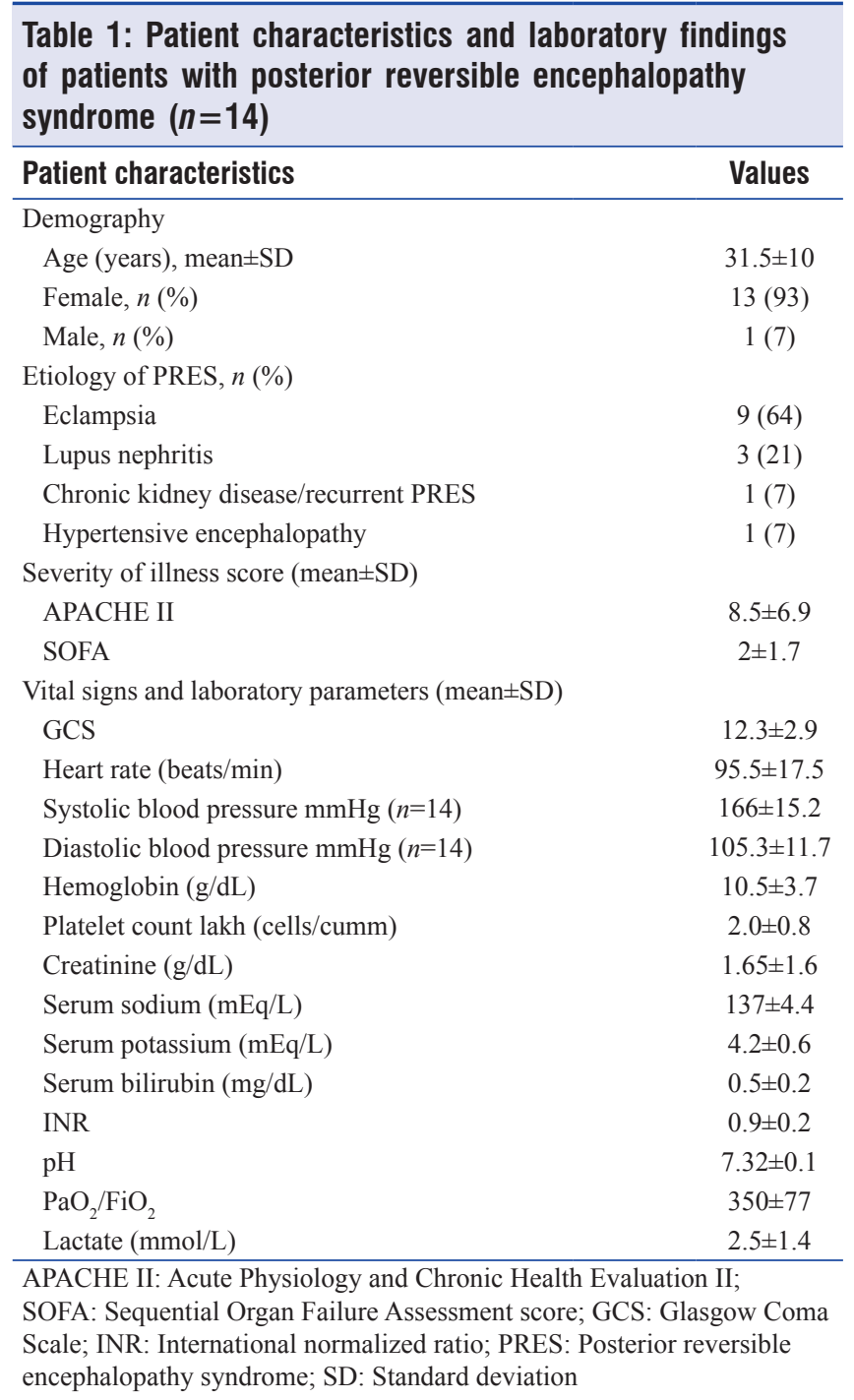


patient had subarachnoid hemorrhage [Figure 3]. International normalized ratio and platelet counts were normal in both the patients.

Eighty-six percent of patients with PRES presented with acute hypertension and their blood pressures were controlled $(<140 / 80 \mathrm{mmHg})$ with intravenous labetalol infusion supplemented with oral antihypertensives [Table 3]. Patients with eclampsia received magnesium sulfate. The median time taken to control blood pressure was $24 \mathrm{~h}$ with an IQR of 15-36 h and median time to regain consciousness was $7 \mathrm{~h}$ (minimum-maximum 0-60 h) with an IQR of 1-21 h. Nearly $57 \%(8 / 14)$ of patients required mechanical ventilation, of which two patients were postoperative cesarean section following antepartum eclampsia, and the remaining six patients were intubated for neurological impairment $(\mathrm{GCS}<8)$. These patients were mechanically ventilated for $3.2 \pm 2.3$ (mean \pm SD) days. ICU average LOS was $4.3 \pm 2.6$ (mean $\pm \mathrm{SD}$ ) days. One patient died (7\%) of 14 patients and this patient was a case of systemic lupus erythematosus (SLE) with lupus nephritis and died of multiorgan failure. Survivors were discharged with no residual neurological deficit (MRS, 0).

\section{Discussion}

PRES can pose a diagnostic dilemma to the treating physician. Acute neurological symptoms in patients with risk factors and brain imaging features of vasogenic edema are highly suggestive of PRES. ${ }^{[2]}$ Obstetricians, intensivists, rheumatologists, neurologists, nephrologists, and transplantation surgeons are more likely to encounter such patients in their practice. ${ }^{[2]}$ Understanding the pathophysiology and diagnosis of PRES is important due to the reversible nature of this syndrome. The majority of patients in our study were female (93\%); this was

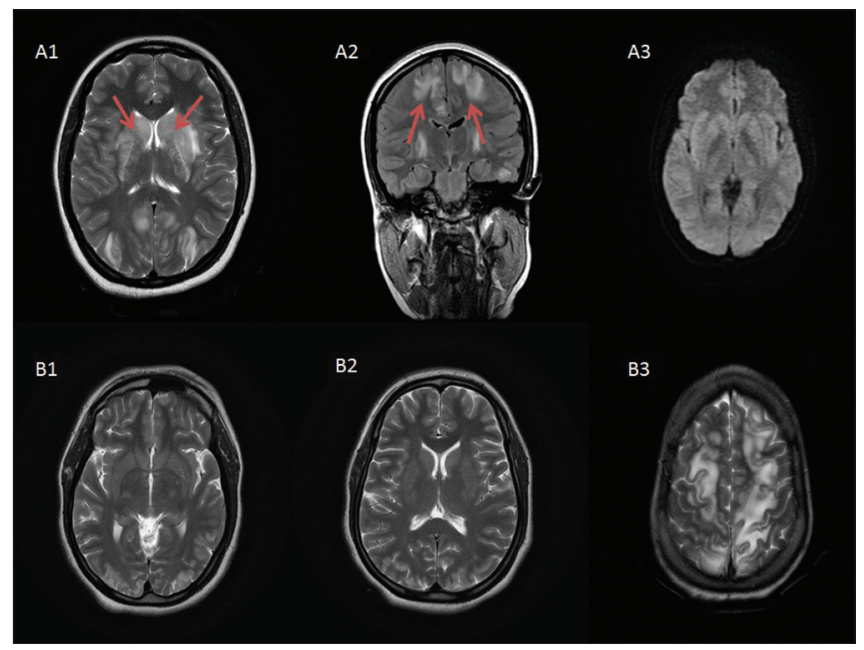

Figure 2: (A1-3) Axial T2-weighted image and coronal T2-FLAIR showing hyperintensities of bilateral basal ganglia, parietal, occipital, and left temporal lobe. Diffusion-weighted images showing no restricted diffusion (patient with eclampsia). (B1-3) Axial T2-FLAIR showing hyperintensities involving bilateral frontal, parietal, temporal, and occipital lobes (postpartum eclampsia with blood pressure 180/110 mmHg) due to case-mix of our study population where $64 \%$ of patients were eclamptic and $21 \%$ of patients were with SLE. Similarly, female preponderance was seen in previous case series from Mayo clinic ${ }^{[1]}(64 \%)$ and China $^{[8]}(80 \%)$.

Recurrent PRES was seen in one patient (7\%); the risk factors for recurrence were ESRD and uncontrolled hypertension. Similar recurrent PRES was reported from Turkey by Ergün et al..$^{[9]}$ in a patient with ESRD. The incidence of recurrent PRES ranges from $3.8 \%$ to $10 \% \cdot{ }^{[1,9-11]}$ Most common presenting

\begin{tabular}{lc}
\hline $\begin{array}{l}\text { Table 2: Magnetic resonance imaging features of } \\
\text { posterior reversible encephalopathy syndrome }(\boldsymbol{n}=\mathbf{1 4})\end{array}$ & $\boldsymbol{n}(\mathbf{\%})$ \\
\hline Site of lesion & $13(92.8)$ \\
\hline Parieto-occipital lobes & $6(42.8)$ \\
Frontal lobe & $3(21.4)$ \\
Cerebellum & $3(21.4)$ \\
Brainstem & $3(21.4)$ \\
Deep white matter (internal/external capsule) & $2(14.2)$ \\
Temporal lobe & $3(21.4)$ \\
Basal ganglia & $1(7.1)$ \\
Focal hyperacute subarachnoid hemorrhage & $1(7.1)$ \\
Hyperacute intraparenchymal hemorrhage
\end{tabular}

\begin{tabular}{lc}
$\begin{array}{l}\text { Table 3: Treatment and outcome of patients with posterior } \\
\text { reversible encephalopathy syndrome }\end{array}$ \\
\hline
\end{tabular}

IV: Intravenous; ICU: Intensive Care Unit; SD: Standard deviation; IQR: Interquartile range; ALOS: Average length of stay

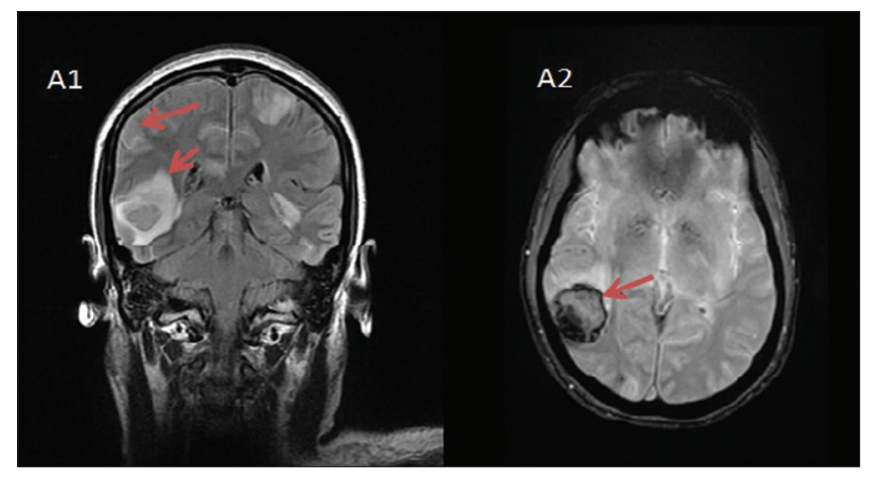

Figure 3: (A1 and 2) Coronal T2-FLAIR and axial gradient-recalled echo showing abnormal signals involving bilateral parietal lobe, occipital lobe, and temporal lobe with acute intraparenchymal hemorrhage in the right temporal lobe and focal subarachnoid hemorrhage in right frontal lobe (antenatal eclampsia presented with a blood pressure of $180 / 120 \mathrm{mmHg}$ ) 
symptoms were seizures (93\%), followed by headache and visual disturbance (43\%). The incidence of seizures in PRES varies between $74 \%$ and $91 \% ;^{[1,8]}$ seizures following encephalopathy is the most common presenting symptom in PRES. ${ }^{[2]}$ Neurological symptoms vary between mild confusion-to-deep coma and status epilepticus. ${ }^{[2]}$ About $14 \%$ of patients presented with status epilepticus; the incidence of status epilepticus was similar to case series from Mayo clinic $(18 \%){ }^{[1]}$ The incidence of headache $(26 \%-87 \%)$ and visual disturbance $(20 \%-62 \%)$ in PRES is quite varied. ${ }^{[1,8]}$

Nearly $57 \%$ of patients required mechanical ventilation for poor GCS; a requirement of intubation and mechanical ventilation in patients with PRES ranges from $32 \%$ to $39 \% .{ }^{[10,12]}$ MRI showed that parieto-occipital region $(92.8 \%)$ was most commonly involved, followed by the frontal lobe $(42.8 \%)$. Fugate et al. ${ }^{[1]}$ reported a similar pattern of involvement of parieto-occipital region $(90 \%)$ and frontal lobe $(77 \%)$ in 115 cases of PRES. Hemorrhage was noted in two patients (14\%): one patient had intraparenchymal hemorrhage (7\%) and other patient had subarachnoid hemorrhage (7\%). The incidence of hemorrhage in PRES ranges from $5 \%$ to $19 \%{ }^{[1,10]}$ and it was associated with coagulopathy and high blood pressure.

The mortality rate in our case series was $7 \%$ and this occurred secondary to sepsis MODS. Mortality in patients with PRES ranges from $3 \%$ to $6 \%$ and this has been attributed to neurological injury secondary to intracranial hemorrhage, posterior fossa edema with brainstem compression, diffuse cerebral edema, and increased intracranial pressure. ${ }^{[2,13]}$ Although residual neurological deficit has been reported in $10 \%-20 \%{ }^{[14,15]}$ of patients with PRES, $93 \%$ of survivors were discharged with no residual neurological deficit (MRS, 0).

Our study has various limitations: first, radiological proof of reversibility was not obtained in our patients due to lack of follow-up MRI in our patients after resolution of neurological symptoms; second, our results were influenced by the case-mix of our patient population, especially eclamptic patients; and finally, the lack of long-term neurological follow-ups in our study group.

\section{Conclusions}

PRES is a reversible disorder; with the timely identification and withdrawal of the precipitating factors, outcomes are better.

\section{Financial support and sponsorship}

Nil.

\section{Conflicts of interest}

There are no conflicts of interest.

\section{RefERENCES}

1. Fugate JE, Claassen DO, Cloft HJ, Kallmes DF, Kozak OS, RabinsteinAA. Posterior reversible encephalopathy syndrome: Associated clinical and radiologic findings. Mayo Clin Proc 2010;85:427-32.

2. Fugate JE, Rabinstein AA. Posterior reversible encephalopathy syndrome: Clinical and radiological manifestations, pathophysiology, and outstanding questions. Lancet Neurol 2015;14:914-25.

3. Bartynski WS, Boardman JF, Zeigler ZR, Shadduck RK, Lister J. Posterior reversible encephalopathy syndrome in infection, sepsis, and shock. AJNR Am J Neuroradiol 2006;27:2179-90.

4. Furukawa M, Terae S, Chu BC, Kaneko K, Kamada H, Miyasaka K. MRI in seven cases of tacrolimus (FK-506) encephalopathy: Utility of FLAIR and diffusion-weighted imaging. Neuroradiology 2001;43:615-21.

5. Kur JK, Esdaile JM. Posterior reversible encephalopathy syndrome - An underrecognized manifestation of systemic lupus erythematosus. J Rheumatol 2006;33:2178-83.

6. Hinchey J, Chaves C, Appignani B, Breen J, Pao L, Wang A, et al. A reversible posterior leukoencephalopathy syndrome. N Engl J Med 1996;334:494-500.

7. Gatla N, Annapureddy N, Sequeira W, Jolly M. Posterior reversible encephalopathy syndrome in systemic lupus erythematosus. J Clin Rheumatol 2013;19:334-40.

8. Ni J, Zhou LX, Hao HL, Liu Q, Yao M, Li ML, et al. The clinical and radiological spectrum of posterior reversible encephalopathy syndrome: A retrospective series of 24 patients. J Neuroimaging 2011;21:219-24.

9. Ergün T, Lakadamyali H, Yilmaz A. Recurrent posterior reversible encephalopathy syndrome in a hypertensive patient with end-stage renal disease. Diagn Interv Radiol 2008;14:182-5.

10. Li R, Mitchell P, Dowling R, Yan B. Is hypertension predictive of clinical recurrence in posterior reversible encephalopathy syndrome? $\mathrm{J}$ Clin Neurosci 2013;20:248-52.

11. Sweany JM, Bartynski WS, Boardman JF. "Recurrent" posterior reversible encephalopathy syndrome: Report of 3 cases - PRES can strike twice! J Comput Assist Tomogr 2007;31:148-56.

12. Lee VH, Wijdicks EF, Manno EM, Rabinstein AA. Clinical spectrum of reversible posterior leukoencephalopathy syndrome. Arch Neurol 2008;65:205-10.

13. Legriel S, Schraub O, Azoulay E, Hantson P, Magalhaes E, Coquet I, et al. Determinants of recovery from severe posterior reversible encephalopathy syndrome. PLoS One 2012;7:e44534.

14. Liman TG, Bohner G, Heuschmann PU, Endres M, Siebert E. The clinical and radiological spectrum of posterior reversible encephalopathy syndrome: The retrospective Berlin PRES study. J Neurol 2012;259:155-64.

15. Postma IR, Bouma A, Ankersmit IF, Zeeman GG. Neurocognitive functioning following preeclampsia and eclampsia: A long-term follow-up study. Am J Obstet Gynecol 2014;211:37.e1-9. 